\title{
A CRITICAL REVIEW OF CHILD CUSTODY EVALUATION REPORTS
}

\author{
James N. Bow and Francella A. Quinnell
}

\begin{abstract}
This study examined 52 child custody reports drafted by doctoral-level psychologists from across the United States to determine (a) the nature, scope, and quality of the evaluation process as reflected in report content; (b) the degree to which practice as documented in reports is congruent with practice as described by survey data; and (c) the manner in which evaluation results are communicated to the court. In general, the findings suggest that evaluation procedures identified in reports are consistent with those described in past survey research and with custody guidelines. Evaluations tend to be court ordered, comprehensive, and well written. Ways in which reports can be improved were identified.
\end{abstract}

One of the most controversial areas of forensic psychology is child custody practice. Numerous authors have criticized the quality of evaluations completed in this area (Melton, Petrila, Poythress, \& Slobogin, 1997; Melton, Weithorn, \& Slobogin, 1985; O'Donohue \& Bradley, 1999; Turkat, 1993). Complaints have included the lack of empirical methods, the inappropriate use of psychological tests, the improper use and interpretation of data, and the lack of usefulness to the court. O'Donohue \& Bradley (1999) even called for a moratorium on such evaluations.

In 1994, two professional organizations promulgated child custody guidelines to promote proficiency in this area. These guidelines, the then-Association of Family and Conciliation Courts' (AFCC's) "Courts Model Standards of Practice for Child Custody Evaluations" and the American Psychological Association's (APA's) "Guidelines for Child Custody Evaluations in Divorce Proceedings" addressed the purpose of the evaluation, preparatory and training issues, and procedural steps. Adherence to these guidelines and the quality of custody evaluations and reports continue to be areas of debate.

Ensuring high-quality child custody evaluations and reports is important for a number of reasons. First, the focus of the evaluation is on the best interests of the child (AFCC, 1994; APA, 1994). As noted by Woody (2000), there is a strong societal need to safeguard the well-being of children; the evaluation should thus fulfill evaluators' legal duty to protect children's best interests. Second, the stress of divorce often results in anguish and tension for family members (Hodges, 1991). This is particularly true in disputed/contested divorces. It is essential, therefore, that the evaluation process minimize the probability of iatrogenic harm (Ackerman \& Ackerman, 1996), that is, evaluators' precipitating or aggravating injury to the parties because of their attitudes, actions, or comments. If the evaluator maintains neutrality, listens to all parties, uses the same standard procedures, and handles/reports data in a sensitive manner, it is hoped this goal can be attained. Third, the conclusions and recommendations made by evaluators significantly impact families. It is imperative for evaluators to con-

\footnotetext{
Authors' Note: The authors wish to acknowledge Joyce Chapman and Arlene Richardson for their secretarial assistance during this project. Correspondence concerning this article should be addressed to James N. Bow, Ph.D., Director of Psychology, Hawthorn Center, 18471 Haggerty Road, Northville, Michigan 48167; e-mail: bow@state. mi.us.
}

FAMILY COURT REVIEW, Vol. 40 No. 2, April 2002 164-176

(C) 2002 Sage Publications 
sider developmental issues, strengths, and weaknesses of the parents and current divorce/ custody research in the evaluation process. Fourth, custody disputes deal with a variety of emotionally charged issues. Consequently, it is important for evaluators to maintain an objective stance, to understand transference and countertransference issues, and to adhere to professional practice parameters. Otherwise, they may risk malpractice suits or board/ ethical complaints. Last, custody evaluators infrequently testify in court (Bow \& Quinnell, 2001a; Melton et al., 1985). The expert's report is usually taken at face value and is not subjected to cross-examination, which further supports the need for high-quality professional work.

A variety of approaches have been used to assess the quality of child custody evaluations. For example, a number of these studies have surveyed the practices and procedures of mental health professionals conducting such evaluations (Ackerman \& Ackerman, 1997; Bow \& Quinnell, 2001a; Keilin \& Bloom, 1986; LaFortune \& Carpenter, 1998). Findings indicate that significant improvements have occurred over the past 15 years. Evaluations have become more comprehensive and sophisticated, incorporating data from multiple collection sources and the application of critical decision-making skills. Evaluators have also become more aware of ethical and risk-management issues.

Survey research has also focused on the legal community's beliefs and attitudes about child custody evaluations (Bow \& Quinnell, 2001b; LaFortune, 1997). Both judges and attorneys preferred court-ordered evaluations and favored psychologists as mental health experts in such matters. Objectivity was noted to be paramount in the evaluation process. Both studies indicated a need for improvement in custody reports. In particular, Bow and Quinnell (2001b) found that judges and attorneys from Michigan favored a more childfocused report that addressed statutory best interests of the child criteria and provided recommendations for custody and visitation. Also, timely completion of the evaluation/report (e.g., 5 to 6 weeks) was highly desired.

These survey studies have some definite limitations in their ability to determine the quality of child custody work. First, survey research relies on retrospective estimates, which may not actually reflect frequency and usage rates of different custody practices and procedures. Second, the methods and procedures reported as being used by evaluators may vary greatly from their actual practices and procedures. Third, survey research does not reflect how data are integrated and presented in a report format.

An actual review of child custody evaluation reports is a more accurate indicator of evaluation practices and procedures. However, this type of research is complicated by confidentiality issues, willingness of mental health professionals to share their work, and lack of readily accessible reports from private practitioners. These factors have deterred needed research in this child custody area.

This study sought to overcome such obstacles and undertook the review of actual custody evaluation reports. Reports best reflect child custody practices and procedures and allow accurate assessment of how data and findings are presented in a report. Because procedures used in child custody evaluations vary among mental health professionals, it was decided that this study would focus only on doctoral-level psychologists. 


\section{METHOD}

\section{IDENTIFICATION OF PARTICIPANTS}

Names of potential participants were obtained from the following sources: an Internet search, public access referral lists from the American Board of Forensic Psychology and the Michigan Society of Forensic Psychology, Friend of the Court (FOC) nominations, and the first author's knowledge of evaluators through conferences, workshops, and articles/books. In addition, psychology members of the Internet Child Custody Evaluators' listserver group were contacted. Overall, 265 potential participants were identified.

\section{SELECTION PROCEDURE}

Each potential participant was sent a letter explaining the nature and purpose of the study and describing the specific requirement for participation, that is, submission of a typical child custody evaluation report, with all identifying information omitted, to the researchers. Prospective participants were also informed that all information would be confidential and data would be analyzed and reported on a group basis only. Those interested in participating were asked to return an enclosed preaddressed stamped postcard and were then sent a packet of materials including cover letter, informational consent form, evaluator's demographic information sheet, $\$ 5$ to cover copying cost, and stamped return envelope. Of the 265 persons contacted, 78 returned the postcard and were sent the packet of materials as described above. Approximately 1 month after forwarding the packet, a reminder postcard was sent requesting return of the completed study documents. Fifty-six individuals returned the requested information; however, only 52 met the study criteria-for example, psychologists performing child custody evaluations. Four individuals were from other disciplines (e.g., social worker, licensed counselor).

\section{DATA COLLECTION}

Data were collected from the demographic information sheet and the child custody evaluation report returned by study participants. Demographic information provided included age, gender, primary work state, educational background, years of experience, and child custody experience. To objectively evaluate the child custody report, a detailed check sheet was developed to collect relevant data to be used for analysis, including the format of the report and areas covered, procedures used in the evaluation process, types of psychological tests used with children and adults, structure of parent-child observations, handling of collateral data sources, and types of recommendations made.

\section{PARTICIPANT DEMOGRAPHICS}

The average age of the participants was 50.47 years $(S D=6.90)$, with a range from 32 to 72. Males constituted $62 \%$ of the sample. All participants were doctoral-level psychologists, with $87 \%$ Ph.D.'s., $11 \%$ Psy.D.'s., and 2\% Ed.D.'s. The vast majority had a major in clinical psychology $(71 \%)$, followed by counseling psychology (15\%), school psychology (4\%), and $10 \%$ other (e.g., forensic psychology, developmental psychology, and child/family psychol- 
ogy). Fourteen percent of participants were diplomates of the American Board of Forensic Psychology. All participants lived in the United States; 23 states were represented. The average length of clinical experience was 21.61 years $(S D=5.92)$, with 13.12 years $(S D=5.25)$ of child custody experience. On average, they devoted $40 \%$ of their practices to child custody work and conducted 22 evaluations per year. In total, they had completed an average of 215 child custody evaluations (median $=130$ ), with a range from 22 to 1,500 .

\section{RESULTS}

\section{REPORT FORMAT}

The overwhelming majority (83\%) of participants used the classic report format versus a letter to the judge ( $13 \%$ ), letter to an attorney $(2 \%)$, or other $(2 \%)$. The reports/letters ranged in total length from 5 to 63 pages, with a mean of 24 pages $(S D=17)$ and median of 18 pages. They could be categorized into three main groups: (a) brief summary reports/letters, usually fewer than 12 pages (38\%); (b) comprehensive, detailed single report, usually exceeding 20 pages (54\%); and (c) individual reports for each family member, usually of 8 to 12 pages, along with a separate summary report, often of 3 to 5 pages $(8 \%)$. The amount of time needed to complete the report(s) ranged from 2 to 88 hours, with a median and mode of 10 hours.

There were indications that $81 \%$ of participants provided court information (e.g., case number, court name), whereas only $44 \%$ provided attorney information. It should be noted that identifying information was deleted or changed for confidentiality purposes; therefore, the inclusion of such information in reports may be underestimated. Sixty percent were initial evaluations (e.g., prior to divorce decree), with the remaining $40 \%$ involving modification of custody or visitation. An overwhelming majority of evaluations were court ordered (88\%). Almost all participants (92\%) separately listed the specific procedures used in the evaluation process. However, of that group, $15 \%$ did not list specific dates for each procedure used, and the majority (65\%) did not report the time involved for each procedure. The number of children reportedly involved in each evaluation process ranged from one to four, with $44 \%$ and $42 \%$ involving one and two child(ren), respectively.

\section{PROCEDURES REPORTED}

Table 1 provides a list of the procedures commonly used in custody evaluations and the percentage of respondents utilizing each procedure. Few participants used initial conjoint interviews; however, all conducted individual interviews with all parents (or parental figures). With the exception of children younger than 5 , interviews also were held with almost all children. Psychological testing of parents (or parental figures) was done in almost all cases, but only about one third of children were tested. In the overwhelming majority of cases, parent-child observations were made, with approximately one third of observations completed during a home visit. Significant others (e.g., spouse, live-together partner, or partner) also were interviewed the vast majority of the time (75\%) but were only occasionally tested (33.3\%). Collateral contacts were most commonly therapists $(77.7 \%)$, when applicable. Interestingly, school personnel were contacted only $62 \%$ of the time when the child was of school age. 
Table 1

Procedures Used in Child Custody Evaluations

\begin{tabular}{lc}
\hline Procedure & Percentage Using Procedure \\
\hline Interview with father & 100.0 \\
Interview with mother & 100.0 \\
Interview with each child & 92.3 \\
Testing of father & 90.4 \\
Testing of mother & 90.4 \\
Parent-child observation in office setting & 82.7 \\
Document review & 78.8 \\
Interview with significant other, if applicable & 75.0 \\
Collateral contacts & \\
Therapist, if applicable & 77.7 \\
Other (e.g., friends, guardian ad litem) & 73.1 \\
Doctor, if applicable & 65.5 \\
School personnel, if applicable & 62.0 \\
Relatives & 51.9 \\
Testing of child(ren) & 38.5 \\
Home visit & 34.6 \\
Testing of significant other, if applicable & 33.3 \\
Initial conjoint interview & 15.4 \\
\hline
\end{tabular}

\section{PSYCHOLOGICAL TESTING}

Adult IQ tests were infrequently administered (see Table 2). When given, an IQ screening measure (e.g., Slosson Intelligence Test, Kaufman Brief Intelligence Test, Shipley-Hartford Institute of Living Scale) was most commonly used. None of the participants used achievement testing with adults. For adult personality assessment, objective tests were preferred over projective measures. Of those administering objective tests, the most frequently used was the Minnesota Multiphasic Personality Inventory (MMPI) (original or second edition) (93\%), followed by the Millon Clinical Multiaxial Inventory (MCMI)-III (44\%). No other objective personality tests were used by more than $10 \%$ of the respondents. Interestingly, respondents indicated they used parenting inventories more than projective techniques. Of those using the former, the preferred instruments were the Parenting Stress Index (59\%) and the Parent-Child Relationship Inventory (55\%). The Parent Satisfaction Scale and Child Abuse Potential Inventory were each used by only $14 \%$ of participants using parenting inventories. Of those administering projective measures, the Rorschach Ink Blot Test was preferred (50\%). The Comprehensive System (Exner, 1993) was preferred over other Rorschach scoring methods by the majority of those participants using the test. Sentence Completion was the next most commonly used projective instrument ( $40 \%$ ), followed by the Thematic Apperception Test (TAT) and Human Figure Drawing (HFD), each used by $20 \%$ of study participants.

Parent-child rating scales were used by less than one third of study participants. The most frequently used scale was the Child Behavior Checklist (40\%), followed by the Conner's Parent Rating Scale (26\%) and Behavior Assessment System for Children (13\%). No more than one participant used any other rating scales.

As shown in Table 2, IQ tests were infrequently administered to children. When used, IQ screenings, such as the Kaufman Brief Intelligence Test or Slosson Intelligence Test, were 
Table 2

Types of Psychological Tests Administered to Adults and Children

\begin{tabular}{lc}
\hline Test Category & Percentage Using Test Category \\
\hline Adults & \\
Objective personality tests & 87.8 \\
Parenting inventories & 44.9 \\
Projective personality instruments & 40.8 \\
Child rating scales & 30.6 \\
IQ tests & 22.4 \\
Achievement tests & 0.0 \\
Children & \\
Projective personality tests & 21.6 \\
Child perception of parent scales & 21.6 \\
Objective personality tests & 19.6 \\
IQ tests & 11.8 \\
Achievement tests & 3.9 \\
\hline
\end{tabular}

preferred by approximately half of study participants. Achievement tests were almost never used, and when used, the Wide Range Achievement Test-Third Edition was chosen. Projective personality measures were used slightly more often than objective tests with children; those who used projective measures preferred the Rorschach Ink Blot Test, Roberts Apperception Test, and Family Drawings, all of which were reportedly used by $27 \%$ of those participants who reported using projective measures. Among the participants using objective tests, the preferred tests were the Millon Adolescent Clinical Inventory (30\%) and the MMPI-Adolescent Version (MMPI-A) (20\%). Child-completed measures of perceptions of parents were used by about one fifth of the participants, with the Bricklin Perceptual Scales (55\%) and the Perception of Relationship Test (45\%) identified as the most frequently used instruments.

Only 1 participant used a custody battery, the Ackerman-Schoendorf Scale for Parent Evaluation of Custody (ASPECT). However, the ASPECT's formal scoring procedure was not followed.

It is important to note that 4 participants mentioned giving psychological tests but did not identify the specific tests. In addition, only $17 \%$ of participants provided test result scores to substantiate their impressions, although the majority (63\%) addressed each test separately rather than globally integrating all test findings.

\section{PARENT-CHILD OBSERVATIONS}

Table 3 outlines the type of parent-child observations reportedly used by study participants. In almost half of the reports, the session was not described in the report (i.e., unspecified type) or was identified only as a "home visit" and could not be classified as unstructured and/or structured. Furthermore, only $35 \%$ specified the time length of the session(s). Time length, when reported, ranged from 20 minutes to 8 hours per session, with a mean of 1.92 hours $(S D=1.94)$. The overwhelming majority of participants $(76 \%)$ observed each parent with all children. The next most common observation format was observing each parent and his or her significant other (e.g., other adult living within the home), with all the children together (18\%). 
Table 3

Characterization of Parent-Child Observation

\begin{tabular}{lc}
\hline Type of Observation & Percentage Using Format \\
\hline Unspecified & 24 \\
Home visit, but unspecified format & 22 \\
Combination of structured and unstructured & 20 \\
Unstructured & 18 \\
Structured & 16 \\
\hline
\end{tabular}

\section{COLLATERAL INFORMATION}

The use of collateral information in the report was also examined. Detailed and specific information from collateral sources was provided by $60 \%$ of the participants, whereas $17 \%$ provided general information (e.g., summary of information without identifying specific source). Eight percent provided a list of collateral contacts but no information regarding their comments/input, and $15 \%$ did not report using any collateral sources in their evaluations.

\section{REPORT COMPONENTS}

Evaluation components commonly discussed in custody reports are provided in Table 4, along with the percentage of study participants who addressed each area. Informed consent or limits of confidentiality issues with their clients were the most frequently overlooked components, with only about one fourth of participants mentioning these issues in their reports. Approximately three quarters of the participants listed the documents reviewed; however, only about two thirds specifically referred to those documents in the body of their reports. Other areas that seemed inadequately covered in the reports were clinical descriptions of the parties (53.8\% provided descriptions) and, even more so, only slightly more than one third of participants documented mental status information. Whereas an overwhelming majority of participants described the reason for the evaluation, almost $12 \%$ failed to address this critical issue. Historical information was given in most reports, with almost all participants focusing on family circumstances and history. However, fewer than half of the participants provided a child history. On the other hand, the vast majority reported on the interview with the child. Although significant others (e.g., spouses, live-together partners, or partner) were usually interviewed (see Table 1), their histories were usually omitted from the reports. Less than half of the participants addressed the best interests of the child. Almost all participants addressed the following areas in their reports: (a) strengths and weaknesses of the parents, (b) summary of findings, (c) general recommendations, and (d) explicit recommendations regarding custody or visitation (e.g., ultimate issue).

\section{RECOMMENDATIONS}

Among those participants who made recommendations (96.2\%), the most common type pertained to physical custody (see Table 5), which was addressed by almost all the participants. Interestingly, recommendations concerning legal custody and visitation, which are both closely intertwined with physical custody, were addressed less often. Therapy for parent(s) was recommended more often than for children. Parenting classes and divorce groups were rarely recommended. 
Table 4

Areas Addressed in Child Custody Evaluation Report

\begin{tabular}{lc}
\hline Report Component & Percentage Using Report Component \\
\hline Recommendations & 96.2 \\
Summary & 94.2 \\
Specific custody or visitation recommendations & 94.2 \\
Family history & 92.3 \\
Reason for referral & 88.5 \\
Parents' strengths and weaknesses & 88.5 \\
Testing of parents & 84.6 \\
Interview of child(ren) & 82.7 \\
Parent-child observation & 76.9 \\
Parents' history & 69.2 \\
Discussion of documents, if listed & 67.4 \\
Documents listed & 63.5 \\
Clinical description of parties & 53.8 \\
Best interests criteria & 48.1 \\
Child(ren)'s history & 48.1 \\
Mental status examination & 38.5 \\
Testing of child(ren) & 38.5 \\
Testing of significant others, if applicable & 35.5 \\
Informed of limits of confidentiality & 28.8 \\
Informed consent provided & 25.0 \\
History of significant other, if applicable & 23.1 \\
\hline
\end{tabular}

Table 5

Types of Recommendations Made in Child Custody Evaluation Report

\begin{tabular}{lc}
\hline Specific Recommendation & Percentage Making Recommendation \\
\hline Physical custody & 92.3 \\
Legal custody & 84.6 \\
Visitation & 80.8 \\
Therapy for parent(s) & 63.5 \\
Therapy for children & 40.4 \\
Guardian ad litem or special master & 28.8 \\
Mediation & 15.4 \\
Parenting classes & 11.5 \\
Divorce group for parents & 5.8 \\
Divorce group for children & 1.9 \\
\hline
\end{tabular}

\section{MISCELLANEOUS ISSUES}

Two of the participants reported that they had previously served in a therapeutic role with the families they evaluated, a situation that is contrary to forensic guidelines regarding multiple relationships. Four participants (8.3\%) wrote test-oriented reports; that is, they gave a variety of psychological tests and relied heavily on test findings. A few participants reported conducting psychological tests but did not address the specific findings of their tests. Two participants wrote very adult-oriented reports with little or no discussion of the child. About $15 \%$ of the participants wrote very short reports (e.g., 8 or fewer pages), whereas $22 \%$ wrote reports of 40 pages or more. 


\section{DISCUSSION}

The present findings are consistent with those of prior survey research focusing on the practices of psychologists in child custody work (Ackerman \& Ackerman, 1997; Bow \& Quinnell, 2001a). In general, evaluations were court ordered, comprehensive, and included data collected from multiple sources. Typical procedures used in the evaluation process were (a) parent and child interviews, (b) parent-child observations, (c) testing of the parents, (d) collateral contacts (including interviews with significant others), and (e) review of documents. Testing was typically used to assess personality functioning and parenting capacity rather than to determine IQ or academic functioning, and it was seen as just one of many data sources. Recommendations regarding physical custody were almost always provided, although legal custody and visitation were addressed somewhat less frequently.

In general, the present findings fail to support the major criticisms of child custody evaluations, such as an overreliance on psychological testing (Melton et al., 1997) and a narrow or selective use of procedures and data (O'Donohue \& Bradley, 1999). However, a small number of evaluations included in this study were problematic and failed to meet professional standards. Such evaluations were adult-focused, predominately test-oriented, or conducted by an evaluator who functioned in multiple roles (e.g., therapist and evaluator). Also, a small number of evaluators ( $12 \%$ ) failed to identify the specific reason for the referral, $8 \%$ did not identify the specific procedures used in the evaluation, $8 \%$ mentioned testing but did not specify the particular tests used, and $15 \%$ did not use collateral contacts. Although not as critical or serious as the aforementioned problems, they are still areas of concern. Such evaluations reflect poorly on the profession and add fuel to the criticisms of child custody work.

The format and content of the child custody evaluation reports also varied widely. This may be due to personal preference and/or the particular needs of the family court system. Nevertheless, some vital information was omitted or scantly addressed, which hinders the reader's understanding of the procedural steps used. For example, informed consent and limits of confidentiality, two areas stressed in custody guidelines (AFCC, 1994; APA, 1994), were addressed in only about one quarter of the reports. These findings contradict those of Bow and Quinnell's (2001a) survey research, in which evaluators indicated almost unanimously that they reviewed informed consent and limits of confidentiality as part of the evaluation process. In consequence, the discrepancy may be due to evaluators' reviewing, but not documenting, these procedures in their reports, an unwise practice from a risk-management standpoint. In the absence of documentation to the contrary, the assumption is often made that the particular procedure was not completed. Therefore, it is imperative that evaluators document this critical aspect of the evaluation process.

Almost 50\% percent of the reports lacked a clinical description of the parties (i.e., how they presented and interacted with the evaluator). This finding was unexpected, considering that a vast majority of evaluators were trained as clinical psychologists. The absence of this information in a significant number of the reports creates concern, because data about each party's presentation and interaction style with the evaluator and status at the time of the evaluations are important in the hypothesis-testing process. Furthermore, because custody disputes and evaluations can create a high degree of stress and tension, with the parties often appearing at their worst, it is vital for this information to be included in the report.

Findings on the handling of documents and collateral sources were also interesting. The AFCC (1994) and APA (1994) guidelines, as well as Ackerman and Ackerman (1996), Gould and Stahl (2000), and Schutz, Dixon, Linderberger, and Ruther (1989), stress the importance of these multiple methods of data collection in custody work. However, only 
slightly more than three quarters of participants mentioned reviewing documents, and even fewer (63.5\%) listed the actual documents they reviewed in their reports. In contrast, Bow and Quinnell's (2001a) survey research indicated that almost all evaluators (98\%) reviewed collateral documents. Again, this may be an issue of evaluators' failure to document what they actually do. It is also noteworthy that of those who listed documents, one third did not refer to those documents in the body of their reports. In consequence, it was difficult to ascertain how those particular evaluators used the document(s) in the evaluation process. In some cases, it may be that the evaluators lack knowledge regarding what material to include and how particular content is best incorporated in the report. This may be particularly applicable to those practitioners who are unaware of the differences between documentation in therapy versus forensic settings. Furthermore, review of documentation and collateral contacts are time-consuming tasks and perhaps are utilized by some evaluators under only certain circumstances when the information to be acquired may illuminate some troublesome aspect of the case.

In regard to collateral contacts, $15 \%$ of participants had no such contacts. This was unanticipated considering the importance of this data-collection method for clarifying allegations and testing hypotheses. Of those participants who reported making collateral contacts, the most common contact was with a party's therapist, if applicable, followed by the "other" category, which included friends and the guardian ad litem. School personnel were contacted only $62 \%$ of the time for school-aged children, which seems low considering the negative impact divorce commonly has on school functioning (Hodges, 1991).

The reporting of collateral information is a sensitive issue, because parents sometimes gain access to the report. If a therapist, teacher, or friend spoke negatively of a parent to the evaluator, or did not support a parent's position, disclosure of these individuals' position may damage their relationship with the parent. Nevertheless, the participants in this study usually included the specific information derived from their collateral sources in their reports. A small subgroup ( $8 \%$ ) listed collateral contacts but did not provide any information regarding their input. This creates confusion for the reader of the report, who cannot determine how the evaluator used contacts' input, if it was used at all. A third way of handling such information, and the second most common method used as demonstrated by study reports, was to list the collateral sources and provide input from them without highlighting each source's particular statements (e.g., stating that a number of collateral sources described Mr. Smith as highly involved with the children). Each method of handling collateral information has pros and cons and may also vary depending on the particular case. Nevertheless, in the end, it is important for the reader of the report to understand the evaluator's data source and how the information contributed to the evaluator's opinions and conclusions.

Another unexpected finding was that less than 50\% of participants included a child history in their reports. This means that vital information about a child's development, medical history, school functioning, and interpersonal relationships was omitted. The primary purpose of the evaluation is to assess the best interest of the child and, in doing so, to assess each child's psychological functioning and developmental needs as well as the ability of each parent to meet those needs. Therefore, information about the child's history is crucial and should be highlighted in each report.

Furthermore, some study participants did not interview young children (younger than 5). Although the nature and format of the interview for this age group may differ from that for older children, valuable information can be gathered about the child's psychological functioning and developmental needs. The child's ability to separate from the parent, interaction style with the evaluator, and level of skill development (e.g., language, motor skills, and 
pre-academic skills) can all be easily evaluated during an interview. Also, the Structured Doll Technique (Palmer, 1983) and other play/games (Schaefer, Gitlin, \& Sandgrund, 1991) are useful for assessment purposes during a clinical interview. This information is valuable in the report for describing the child's psychological and developmental needs, as emphasized in the child custody guidelines (AFCC, 1994; APA, 1994).

In general, psychological test findings were not given undue weight and were viewed as one data source. Findings on the use of psychological tests in this study showed similar trends to those found in Quinnell and Bow's (2001) survey research. Adult objective tests remain widely used, with the MMPI-2 and MCMI-III the most commonly administered. Parenting scales were the next most frequently used instruments. Child perception scales have gained popularity too. Increased use of both of these scales indicates a greater interest in the parent-child relationship and in discerning parenting capacity, as stressed by child custody guidelines (AFCC, 1994; APA, 1994). The Rorschach was the most popular projective instrument, but only a slight majority of participants referred to using the Comprehensive System (Exner, 1993) for scoring. The latter is surprising considering the nature of the evaluation setting, that is, forensic (McCann, 1998). The use of IQ and achievement tests continues to decline, which is appropriate considering they do not usually address the legal issues.

Reporting of the parent-child observation in the reports contained the least amount of detail. This is probably due to the lack of standard procedures for conducting such observations, although almost all participants reportedly performed them in an office setting and/or during a home visit. Again, child custody guidelines (AFCC, 1994; APA, 1994) stress the importance of evaluating the interaction between child and parent. To neglect such a procedure in a child custody evaluation would seem indefensible (Gould \& Stahl, 2000). However, more research is needed in this area to increase the usefulness, accuracy, reliability, and validity of conducting and reporting such observations.

The reports in this study provide information that allows us to assess some of the important areas identified by the legal profession (Bow \& Quinnell, 2001b). Two areas identified as very important by the legal profession, strengths and weaknesses of the parents and recommendations about custody and visitation, were well addressed. However, other important areas, legal criteria (e.g., best interests of the child criteria) and child's history, were omitted by more than $50 \%$ of the evaluators. The former may be due to some states' lacking explicit statutory criteria. When applicable, it is important for reports to include these elements in the evaluation and recommendation process.

Another point of contention between the legal profession and custody evaluators has been the length of the evaluation report. Reports by participants in this study averaged around 20 pages. However, a few reports (6\%) were extremely long and simply overkill-including every family and historical detail-and burdensome to read. Considering the time constraints of attorneys and judges, it is highly unlikely they would read such lengthy reports. According to Bow and Quinnell's (2001b) study, judges and attorneys prefer much shorter reports (10 to 12 pages). The legal profession wants a child-focused report that succinctly addresses the major legal issues before the court (e.g., child's needs, parents' strengths and weaknesses in meeting those needs, child custody criteria, and recommendations regarding custody and visitation). It is imperative that child custody evaluators keep in mind the needs of their audience, that is, busy lawyers and judges, when writing reports for the family court.

In regard to limitations of the study, the sample was not reflective of all child custody evaluators. The sample was limited to psychologists, who as a group were highly educated and experienced, and $14 \%$ of whom were diplomates of the American Board of Forensic Psy- 
chology. The vast majority of them worked in private practice in an urban area. Therefore, these factors need to be considered in the interpretation of the findings.

In conclusion, the actual custody evaluation procedures used by doctoral-level psychologists in this study closely matched the findings of previous survey research. The typical evaluation was comprehensive, used multiple sources of data, and closely adhered to procedures outlined in child custody guidelines. Although custody reports were generally well written, a small number lacked adequate coverage of some critical areas. Areas in need of improvement include (a) documentation of informed consent (including lack of confidentiality), (b) provision of clinical descriptions of the parties, (c) listing of documents reviewed, (d) identification and documentation of collateral contact with school personnel, (e) detailed description of parent-child interactions, (f) inclusion of child history, and $(\mathrm{g})$ addressing relevant legal criteria (e.g., best interests of the child). By incorporating these suggestions for improving the quality of reports, it is hoped evaluators will better serve the family court and reduce their risk of malpractice or board/ethical complaints.

\section{REFERENCES}

Ackerman, M. J., \& Ackerman, M. (1996). Child custody evaluation practices: A 1996 survey of psychologists. Family Law Quarterly, 30, 565-586.

Ackerman, M. J., \& Ackerman, M. (1997). Custody evaluation practices: A survey of experienced professionals (revisited). Professional Psychology: Research and Practice, 28, 137-145.

American Psychological Association. (1994). Guidelines for child custody evaluations in divorce proceedings. American Psychologist, 49, 677-682.

Association of Family and Conciliation Courts. (1994). Courts model standards of practice for child custody evaluation. Family and Conciliation Courts Review, 32, 504-513.

Bow, J. N., \& Quinnell, F. A. (2001a). Psychologists' current practices and procedures in child custody evaluations: Five years after American Psychological Association guidelines. Professional Psychology: Research and Practice, 32, 261-268.

Bow, J. N., \& Quinnell, F. A. (2001b). Critique of child custody evaluations by the legal profession. Manuscript submitted for publication.

Exner, J. E. (1993). The Rorschach: A comprehensive system: Vol. 1. Basic foundations (3rded.). New York: Wiley.

Gould, J. W., \& Stahl, P. M. (2000). The art and science of child custody evaluations: Integrating clinical and forensic mental health models. Family and Conciliation Courts Review, 38, 392-414.

Hodges, W. F. (1991). Interventions for children of divorce: Custody, access, and psychotherapy (2nd ed.). New York: Wiley.

Keilin, W. G., \& Bloom, L. J. (1986). Child custody evaluation practices: A survey of experienced professionals. Professional Psychology: Research and Practice, 17, 338-346.

LaFortune, K. A. (1997). An investigation of mental health and legal professionals' activities, beliefs, and experiences in domestic courts: An interdisciplinary survey. Unpublished doctoral dissertation, University of Tulsa, Oklahoma.

LaFortune, K. A., \& Carpenter, B. N. (1998). Custody evaluations: A survey of mental health professionals. Behavioral Sciences and the Law, 16, 207-224.

McCann, J. T. (1998). Defending the Rorschach in court: An analysis of admissibility using legal and professional standards. Journal of Personality Assessment, 70, 125-144.

Melton, G. B., Petrila, J., Poythress, N. G., \& Slobogin, C. (1997). Psychological evaluations for the court (2nd ed.). New York: Guilford.

Melton, G. B., Weithorn, L. A., \& Slobogin, C. (1985). The community mental health centers and the court: An evaluation of community-based forensic services. Lincoln: University of Nebraska Press.

O'Donohue, W., \& Bradley, A. R. (1999). Conceptual and empirical issues in child custody evaluations. Clinical Psychology: Science and Practice, 6, 310-322.

Palmer, J. O. (1983). The psychological assessment of children. New York: Wiley. 
Quinnell, F. A., \& Bow, J. N. (2001). Psychological tests used in child custody evaluations. Behavioral Sciences and the Law, 19, 491-501.

Schaefer, C. E., Gitlin, K., \& Sandgrund, A. (1991). Play diagnosis and assessment. New York: Wiley.

Schutz, B. M., Dixon, E. B., Lindernberger, J. C., \& Ruther, N. J. (1989). Solomon's sword: A practical guide to conducting child custody evaluations. San Francisco: Jossey-Bass.

Turkat, I. D. (1993). Questioning the mental health expert's custody report. American Journal of Family Law, 7, 175-179.

Woody, R. H. (2000). Child custody: practice standards, ethical issues, and legal safeguards for mental healthprofessionals. Sarasota, FL: Professional Resource.

James N. Bow received his Ph.D. from the University of Michigan. He is director of psychology at Hawthorn Center and a consultant and instructor for the Child Custody Program at Wayne State University, School of Medicine, Department of Psychiatry and Behavioral Neurosciences.

Francella A. Quinnell received her Ph.D. from the University of Wisconsin at Milwaukee. She was previously a predoctoral intern at Hawthorn Center and Wayne State University, School of Medicine, Department of Psychiatry and Behavioral Neurosciences. 